\title{
INESPERADAS SINERGIAS E O SUB-ÓTIMO: BRICOLAGEM E EFETUAÇÃO NO EMPREENDEDORISMO DE ESTILO DE VIDA
}

Edmilson Lima ${ }^{1}$

Reed Nelson ${ }^{2}$

Rose Mary Almeida Lopes ${ }^{3}$

\footnotetext{
${ }^{1}$ Programa de Pós-Graudação em Administração / Universidade Nove de Julho

${ }^{2}$ Endowed Chair in Innovation \& Entrepreneurship / B.I. Moody III College of Business Administration / University of Louisiana at Lafayette

${ }^{3}$ ANEGEPE
} 


\section{BRICOLAGEM E EFETUAÇÃO NO EMPREENDEDORISMO DE ESTILO DE VIDA}

Resumo: Praticamente nada se sabe sobre as sinergias entre bricolagem, efetuação e suas soluções sub-ótimas principalmente no empreendedorismo cuja ocorrência se baseia muito na efetuação, como se vê no empreendedorismo de estilo de vida (EEV). O artigo ataca essa necessidade de pesquisa reconhecendo o relevante papel do EEV (principalmente do esportivo) por conciliar bem-estar e trabalho, além de levar melhor qualidade de vida a muitas pessoas. O objetivo do artigo é elucidar como ocorrem as inesperadas sinergias entre a bricolagem, a efetuação e suas soluções sub-ótimas no empreendedorismo, em particular no EEV, aparentemente sob o reinado (quase) exclusivo da efetuação. A pesquisa qualitativa foca cinco casos de EEV esportivo variando de empreendedorismo empresarial a social. Os dados foram coletados com entrevistas semiestruturadas. Os resultados incluem novos conceitos, a caracterização de fases do desenvolvimento do EEV e da centralidade da identidade dos empreendedores, com revelações de impacto para a prática e a pesquisa.

Palavras-chave: Efetuação. Bricolagem. Empreendedorismo de estilo de vida (EEV). Identidade.

\section{Introdução}

A relevância da efetuação e da bricolagem empreendedoras para a compreensão e o aperfeiçoamento do processo empreendedor já foi confirmada por numerosos estudos a partir respectivamente das contribuições inaugurais de Sarasvathy (2001) e Baker e Nelson (2005). O caráter complementar das duas como subprocessos construtores do processo empreendedor, além do caráter promissor de se estudar as interseções delas, é destacado por estudos como os de Fisher (2012), Hindle e Senderovitz (2010) e Welter, Mauer e Wuebker (2016). Os estudos qualitativos de caso único de Nelson e Lima (2019) e Servantie e Rispal (2018), bem como a pesquisa com múltiplos casos de Scazziota (2019), foram adiante. Caracterizaram sinergias e interseções dos subprocessos em diferentes fases de ocorrência do empreendedorismo social ou empresarial e confirmaram o carácter promissor do aprofundamento do estudo sobre o tema.

Apesar dos avanços já feitos, falta conhecimento detalhado sobre interseções, complementaridades e sinergias da efetuação com a bricolagem nos diversos tipos de empreendedorismo. Falta também superar a necessidade de aprofundamento dos estudos da efetuação em relação com outros modos de se empreender (Grégoire e Cherchem, 2019), como a bricolagem (Welter et al., 2016). O mesmo se diz sobre a bricolagem, em particular quanto a seu potencial de prevalecer ou substituir outros comportamentos empreendedores, pois é comum que o conceito seja abordado isoladamente nas pesquisas (Stinchfield et al., 2013). Muito pouco se sabe também sobre as referidas sinergias nos tipos de empreendedorismo cuja ocorrência conta sobremaneira com a efetuação, condição que se poderia imaginar como deixando pouco espaço para a bricolagem. Esse é o caso do empreendedorismo de estilo de vida (EEV), habitualmente realizado com intensa utilização de meios efetuais em boa parte já disponíveis ao empreendedor antes que comece a empreender, em particular da identidade, que se projeta como definidora do que e como empreender (Lima e Lopes, 2019). A identidade destaca-se dentre os meios efetuais aproveitados pelo empreendedor de estilo de vida. Cultivar, aproveitar e até mesmo compartilhar a identidade pela qual se tem tanto apreço em um estilo de vida (EV) prazeroso é uma finalidade central do EEV.

Um exemplo desse tipo de empreendedorismo ocorreria com um vegano aproveitando seus meios pré-existentes ao empreendedorismo, como um hobby em culinária, seus conhecimentos sobre o veganismo, sua rede de relações e sua própria identidade para abrir e desenvolver um restaurante vegano. A efetuação refere-se ao comportamento empreendedor pautado por um levantamento que o empreendedor faz de possíveis efeitos que ele pode obter usando meios que controla especificamente, quem ele é (identidade), quem ele conhece (relações) e o que ele sabe (conhecimento) - definidor de objetivos e ações viáveis com nível de risco limitado a perdas aceitáveis (Sarasvathy, 2001, 2008; Sarasvathy, Foster e Ramesh, no prelo). Exemplos adicionais de

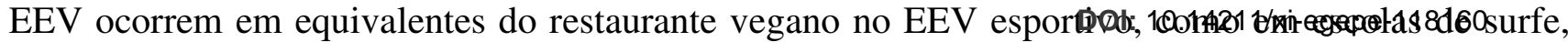


empreendedor quanto ao EV que escolheu priorizando o bem-estar, normalmente relativos à autorrealização e ao alinhamento entre trabalho, vida pessoal, valores e interesses familiares (Ateljevic e Doorne, 2000, Johannisson, 2004; Maritz e Beaver, 2006; Nash e Stevenson, 2004) ${ }^{1}$.

Este artigo explora o alto potencial de contribuição oferecido pelo fato de o EEV ter um importante papel nas sociedades atuais e ainda não ser estudado sob a luz de teorias especificamente do campo do empreendedorismo que mostram alta afinidade com o fenômeno, em especial a efetuação. O EEV tem raízes muito antigas. Supostamente, já havia intensas atividades precursoras dele nas atividades envolvidas na preparação de atletas para as primeiras olimpíadas e na criação de cavalos para esportes equestres da Antiguidade. Isso já criava a possibilidade de se desenvolver um negócio ou atividade social voluntária aproveitando-se meios efetuais de um EV prévio e conexo a apoiar com os ganhos obtidos. Contudo, é nova a ampla dimensão que o EEV apresenta atualmente quanto ao interesse por ele, sua ocorrência e sua geração de benefícios.

Empreender em alinhamento com um EV desejado (e geralmente prazeroso) tem se tornado cada vez mais importante nas sociedades contemporâneas, inclusive para se evitarem insatisfações comuns em ocupações tradicionais. $\mathrm{Na}$ atualidade, populações maiores têm muito mais empreendedores, empregados, famílias e clientes a se beneficiar do EEV. No campo esportivo, por exemplo, estão entre os benefícios do EEV soluções para as disseminadas doenças do sedentarismo, depressão e os problemas de atividades físicas inadequadas. Também há efeitos multiplicadores para além dessa rede básica de pessoas devido à propagação feita por meio de internet e aplicativos online por empreendedores e desportistas entusiasmados. Multidões podem fazer atividades físicas profissionalmente orientadas e viver com mais saúde, como se vê em maratonas internacionais recentes com mais de 45 mil atletas a cada edição.

Intuitivamente, poder-se-ia imaginar que atividades em que há intensa contribuição da efetuação, como o EEV esportivo, tenderiam a não ter espaço para a bricolagem, ainda que em condições de alta restrição de recursos, campo fértil principalmente para a bricolagem. A bricolagem empreendedora é Poder-se-ia também conjecturar que o intenso aproveitamento de fartos e desenvolvidos meios efetuais disponíveis, que são considerados como indutores de expertise e qualidade em atividades empreendedoras (Sarasvathy, 2001), repeliriam a bricolagem, que é afeita a soluções sub-ótimas e a jeitinhos. A bricolagem empreendedora é aqui definida como "virar-se com o que se tem aplicando-se novas combinações dos [escassos e/ou pouco adequados] recursos à mão a novos problemas e novas oportunidades" (Baker e Nelson, 2005; tradução nossa). Justamente, a pesquisa aqui apresentada, baseada no estudo qualitativo de cinco casos de EEV esportivo variando do empreendedorismo social ao empresarial, refuta essas duas tendências intuitivas e ataca a necessidade de pesquisa configurada acima. $\mathrm{O}$ artigo foca em especial a ocorrência das soluções subótimas (em condições inferiores ao recomendável), típicas na bricolagem e relevantes, mas contraintuitivas e quase inexploradas, na pesquisa sobre a efetuação.

Este artigo tem por objetivo elucidar como é possível a bricolagem empreendedora e a efetuação, assim como suas soluções sub-ótimas, terem inesperadas sinergias no EEV, que está aparentemente sob o reinado (quase) exclusivo da efetuação. O uso de uma amostra de casos com essa variedade de tipos de organização, sociais e não sociais, visa a somar a trabalhos como os de Nelson e Lima (2019), Scazziota (2019) e Serventie e Rispal (2018) novos conhecimentos transcendentes ao contexto específico do empreendedorismo social.

\footnotetext{
${ }^{1}$ A palavra "ganhos" nessa definição, ao invés de "lucros", é uma pequena subversão de nossa parte. Há a tradição em pesquisa de exclusiva associação do EEV a atividades cujo lucro dá sustentação ao estilo de vida escolhido. Mas devemos aceitar que outros tipos de ganho, não só o lucro, possam viabilizar ou sustentar um dado estilo de vida. Uma pessoa, tendo ou não alguma atividade remunerada, pode atuar como empreendedor social (ex.: diretor não remunerado de uma associação) e ter essa atividade não apenas como viabilizadora de seu estilo de vida escolhido. A atividade pode também ser um âmbito de ampla vivência e compartilhamento diretamente do estilo de vida em si, como se vê em casos de organizações sociais esportivas BO|⿴囗十)
} 
O conceito de efetuação foi desenvolvido como o contrário da noção de causação. Esta referese à escolha, busca e emprego de meios para se obter os efeitos desejados, segundo um objetivo definido a priori, com uso de previsão e outros aspectos da racionalidade formal. Não dependendo de previsão, a efetuação é particularmente útil em ambientes imprevisíveis e de incerteza, principalmente quando o empreendedor precisa se limitar a empreender usando os recursos a seu alcance (Sarasvathy e Dew, 2005). Se as características da efetuação fazem com que ela seja útil em situações de alta restrição de recursos, tal utilidade (e a compatibilidade) é ainda maior na bricolagem, um conceito clara e explicitamente desenvolvido para se explicar como é possível "fazer algo a partir do nada" no empreendedorismo (Baker e Nelson, 2005). Ambas tendem assim a ser particularmente relevantes para a compreensão do empreendedorismo em contextos, áreas e/ou países marcados por carências, como o Brasil, principalmente no início de empreendimentos - dada a alta restrição de recursos típica dessa fase. Essa fase recebe atenção neste artigo. Alguns estudos indicam ambas as abordagens como promissoras para o estudo do EEV, visto que esse tipo de empreendedorismo não se enquadra no modelo schupeteriano, baseado na causação.

$\mathrm{O}$ EEV refere-se à realização de atividades empreendedoras que viabilizam o EV escolhido pelo empreendedor priorizando o bem-estar dele e das pessoas com quem ele mais se importa, como sua família (Breysse, 2016; Johannisson, 2004; Maritz e Beaver, 2006; Nash e Stevenson, 2004). O EEV implica, portanto, atividades empreendedoras regidas predominantemente pelo projeto pessoal e pelos valores do empreendedor, tendo os ganhos financeiros ou outras formas de ganho buscadas o objetivo principal de sustentar o EV (Breysse, 2016; Johannisson, 2004). Nesse sentido, o EEV traz em seu âmago o contínuo esforço de solução do desafio de conciliação entre trabalho e bem-estar e frequentemente dá a ele respostas criativas e produtivas.

É frequente a pré-existência de um EV de que não se abre mão e o ingresso em atividades empreendedoras propiciadas por (e propícias a) ele. A literatura em EEV tem se concentrado nessa situação (não na de um novo EV por vezes acompanhando um novo negócio) e é nela que também se enquadra o presente trabalho. Nessa opção, normalmente, o EV tomou anos para se firmar num hobby, esporte e/ou gosto por artes e vinhos, dentre outras possibilidades. O empreendedor, assim, tende a ter um útil avanço na curva de aprendizagem e no desenvolvimento de diferentes capitais (econômico, social, cultural, simbólico - Bourdieu, 1984) propícios a atividades focadas ao empreender (Daskalopoulou e Skandalis, 2018). Já tem ao menos parte dessas atividades como marcas relevantes e modeladoras de sua identidade, seus conhecimentos e suas relações.

Já podendo aproveitar esses diferentes meios efetuais (Sarasvathy, 2001) desenvolvidos com seu EV, um ator tenderá a ter facilitado o empreendedorismo em alinhamento com o EV em comparação com outros modos de se empreender. Tal alinhamento é também uma oportunidade frequentemente reconhecida pelo empreendedor como atrativa por lhe permitir conciliar bem-estar e trabalho no EEV. Esses atrativos tendem a dar uma forte marca de efetuação ao EEV, principalmente na fase inicial deste -aparentemente tornando inesperada e contraintuitiva a bricolagem no EEV.

Com seu conjunto de características distintivas, o empreendedor de estilo de vida mostra motivações e comportamentos específicos diferentes do que se vê no empreendedorismo clássico (Breysse, 2016). Trata-se aqui de um empreendedor não convencional (Guercini e Cova, 2018). Ele não se enquadra na abordagem estrita e schumpeteriana que fundamenta o empreendedorismo clássico - adepta da causação e que pressupõe que o empreendedor progride linearmente com busca e identificação de uma oportunidade, tomada de decisão com fixação de objetivos, obtenção de recursos e ações empreendedoras (Carter, Gartner e Reynolds, 1996). Segundo Cova e Guercini (2016), tal fato torna particularmente promissoras para o EEV as explicações alternativas da efetuação (Sarasvathy, 2001) e da bricolagem (Baker e Nelson, 2005).

Um papel importante da bricolagem é o de aumentar a autosuficiência nas iniciativas empreendedoras, especialmente nas condições de recursos mais restritos (Grivins et al., 2017). Assim, não é raro que a efetuação alimente a bricolagem e vice-versa na geração de autosuficiência e no 
aproveitamento dos meios, ainda que escassos, que se tem em mãos.

Assim como o presente artigo, há mais publicações que já contrariam a participação contraintuitiva da bricolagem onde reina a efetuação, como no EEV. A inesperada sinergia entre ambos não apenas pode ocorrer, como também parece não ser rara, inclusive no EEV. Vê-se a sinergia, por exemplo, em um caso de empreendedorismo esportivo classificável como EEV citado por Heilbrunn (2019). Esse autor trata da bricolagem empreendedora realizada como subversão sob severas restrições institucionais e de recursos por refugiados africanos em um campo de detenção israelense. $\mathrm{O}$ detento chamado Hallas explora a sinergia com sua microempresa social. Inconformado com os riscos de depressão dos detentos por falta de ocupação, pôs-se a empreender com uma academia de ginástica clandestina dando seu jeito frente a muitas restrições e servindo-se de competências vindas de seu EV esportivo pregresso: "Combinei aquilo em que sou bom com o que os outros precisam e criei sob pressão a ideia ligada a esportes. Acho que estou fazendo algo útil para muitas pessoas e também faço algum dinheiro, de modo a comprar comida e outras coisas para mim fora do campo" (p. 11; tradução nossa).

\subsection{A Bricolagem e o Sub-Ótimo}

A compreensão do que é a bricolagem empreendedora soma alguns aspectos à formulação original do conceito de bricolagem feita por Lévi-Strauss (1962), ampliando-a de "virar-se usando o que se tem em mãos" para "virar-se com o que se tem aplicando-se novas combinações dos recursos à mão a novos problemas e novas oportunidades" (Baker e Nelson, 2005; tradução nossa). Além dos importantes termos "recursos" e "oportunidades", essa nova definição inclui novas combinações e novos usos, ao invés do simples reuso ou varredura de recursos úteis.

O aspecto mais influente da contribuição de Baker e Nelson (2005) reside numa descrição detalhada sobre como os empreendedores realizam a bricolagem segundo um estudo empíricoindutivo. O conceito consiste em vários elementos, alguns dos quais têm sido amplamente estudados em pesquisas subsequentes, outros sendo negligenciados nos estudos posteriores. Para nosso estudo, são relevantes os seguintes componentes da bricolagem empreendedora (Baker e Nelson, 2005):

- Uma coletânea (que alguns chamariam de "tralha"): empreendedores que realizam bricolagem juntam uma diversificada coletânea de quinquilharias descartadas ou adquiridas a baixo preço pensando que elas podem ser úteis um dia. A coletânea varia em tamanho e diversidade dependendo do uso da bricolagem feito pelo empreendedor.

- Uso de elementos físicos úteis, mas fora de padrão: contando prioritariamente com sua coletânea e, em seguida, com contribuições vindas de sua rede de relação imediata ou da varredura de seus recursos eventualmente úteis, os bricolores usam materiais rústicos, descartados ou fora de padrão para fins diferentes daqueles projetados inicialmente.

- Teste de limitações institucionais: os empreendedores que fazem bricolagem desconsideram ou alargam a conformidade com formalidades, como códigos, normas e requerimentos profissionais.

- Papéis multiplex: os bricolores misturam papéis de vendedor, cliente e trabalho, além de vender para ou comprar de clientes, funcionários e amigos. Os laços sociais multiplex são a norma entre os bricolores.

- Habilidades amplas e adquiridas em autodidatismo: os bricolores preferem aprender fazendo do que por treinamento e obtenção de credencias formais. Orgulham-se de sua habilidade de realizar uma variedade de tarefas em diferentes negócios e especialidades.

Esses aspectos da bricolagem empreendedora são conducentes a soluções sub-ótimas, o que faz com que o bricolor tenha o sub-ótimo como marca de seu modus operandi. Por exemplo, papéis multiplex podem dar a impressão de falta de profissionalismo ou estar de fato fora de parâmetros de profissionalismo, como no caso de pessoas do círculo de relações familiares ou íntimas atuarem também como clientes, fornecedores e/ou empregado - o que fere o clássico e difundido princípio da impessoalidade na administração. $\mathrm{O}$ autodidatismo encerra o risco aprendizagem de procedimentos

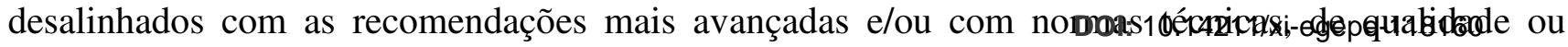


padrão tende a aumentar possibilidades de erro e acidente.

A grande maioria dos estudos da bricolagem foca aspectos positivos da bricolagem como um processo que permite que os empreendedores façam acontecer na adversidade, criando novas e não usuais combinações dos recursos que têm à mão para oferecer novas soluções de produtos e serviços a baixo custo (Senyard et al., 2014). No entanto, como já se viu quanto à improvisação (Moorman e Miner, 1998), a teoria da bricolagem já alertou que os processos e resultados da bricolagem estão particularmente sob risco de não serem adequados, seguros e benéficos (Baker, Miner e Eesley, 2003; Baker e Nelson, 2005; Ciborra, 1996; Kickul et al., 2018; Lanzara, 1999; Senyard, Baker e Davidsson, 2009; Senyard et al., 2014). Seu uso continuado cria o hábito da tentativa e erro e consequente ineficiência, com processos marcados pela confusão (Ciborra, 1996). Kickul et. al. (2018) notaram que a excessiva dependência da bricolagem pode impedir a identificação de atrativos mercados e oportunidades, além de modos adicionais de obtenção de recursos para soluções e inovações. Pode também haver outros efeitos negativos, como 1. esforços desperdiçados; 2. falta de desenvolvimento cumulativo devido ao excessivo emprego de soluções únicas/ customizadas, e 3. falha em atrair e manter fornecedores e clientes importantes e exigentes em termos de qualidade (Senyard et al., 2014). Tudo isso mostra que os empreendedores precisam distinguir quando lançar mão de outras formas de uso e de obtenção de recursos (Bacq et al., 2015).

\subsection{A Efetuação e o Sub-Ótimo, com Destaque para a Identidade}

Sarasvathy e seus co-autores (ex.: Sarasvathy et al. 2014, Sarasvathy 2001) examinaram originalmente como empreendedores expertos (expert entrepreneurs) utilizam seus próprios meios e obtêm o comprometimento de stakeholders para produzir novos produtos, mercados, negócios e oportunidades, enfrentando variadas pressões. Gradualmente, contudo, essa noção inicial foi se dissipando na literatura e a efetuação foi também estudada em associação com empreendedores novatos e outros não tão experientes. Como já adiantamos, a abordagem efetual implica o levantamento de possíveis efeitos que podem ser gerados a partir da consideração feita pelo empreendedor de "quem ele é" (identidade), "quem ele conhece" (rede de relação) e "o que ele sabe" (conhecimento).

Adicionalmente à avaliação dos objetivos e possíveis ações permitidos por seus meios, o empreendedor restringe suas iniciativas à opções ligadas a uma perda máxima aceitável caso fracasse, buscando minimizar seus riscos (Sarasvathy, 2001, 2008). Deixando de lado a previsão, a efetuação se diferencia da abordagem causal, na qual o ator trabalha de modo racional, elaborando um plano em que ele faz previsões e define inicialmente os objetivos para, em seguida, pensar e obter os meios cuja aplicação pode levar ao cumprimento dos objetivos (Sarasvathy e Dew, 2005).

Sarasvathy e colaboradores caracterizaram indutivamente cinco princípios que descrevem a ocorrência da efetuação: perda aceitável, pássaro na mão, colcha de retalhos (crazy quilt), limonada e piloto no avião (Read et al. 2009; Sarasvathy 2001). O princípio da perda aceitável refere-se a realizar iniciativas empreendedoras cujo fracasso eventual estimado possa levar no máximo a perdas previamente consideradas aceitáveis. O pássaro na mão concerne à preferência do ator por utilizar meios possuídos e controlados por ele mesmo. A colcha de retalhos é uma alusão à junção em torno de uma mesma iniciativa de parceiros variados (como um patchwork de colaboradores) e autoselecionados cultivados pelo efetuador. A limonada transmite a ideia de que os efetuadores exploram os reveses como recursos, "fazendo do limão uma limonada". O piloto no avião refere-se à preferência do efetuador por moldar seu ambiente segundo seus propósitos ao invés de adaptar-se ao ambiente.

Uma das frentes necessárias para o avanço dos estudos da efetuação é a da análise de seus possíveis efeitos indesejáveis (Arend, Sarooghi e Burkemper, 2015; Grégoire e Cherchem, 2019). Justamente, tais efeitos são um dos aspectos que tratamos no presente trabalho, mais especificamente no que se refere a abordagens, iniciativas e soluções sub-ótimas ocorridas na (ou pela) efetuação que

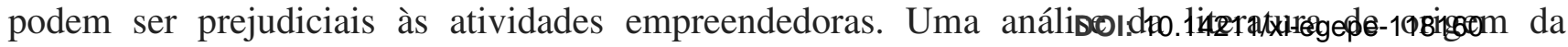


bricolagem (Baker e Nelson, 2005). Ao contrário, já a partir de sua associação inicialmente à expertise, a efetuação tem maior afinidade com a busca da alta qualidade e do profissionalismo de ações e resultados. Contudo, ela pode transportar ao empreendedorismo características desfavoráveis dos meios efetuais que explora. Há também moduladores idiossincráticos do modo de efetuar (ex.: pulsões, interesses, preferências e características pessoais do empreendedor) que podem levar ao subótimo na efetuação. Um exemplo possível seria algum tipo de compulsão, como a mesquinhez inibidora da compra de mais recursos, que levasse um empreendedor a insistir demasiadamente em se ater ao uso de meios efetuais (portanto, já possuídos por ele mesmo) quando isso já seria contraprodutivo. Essa seria um situação de exagero na aplicação do princípio do pássaro na mão.

Outro exemplo de efeito indesejável da identidade vem de nossa pesquisa de campo, em que identificamos uma empreendedora a afirmar enfaticamente que um dos problemas de seu jeito de empreender vem de sua identidade de atleta. Segundo ela, um atleta não precisa divulgar resultados, pois estes já se mostram claramente em competições, como o número de pontos que ela fazia no basquete profissional. Ela tomou então esse fato como causa da fraca captação de parceiros e de financiamento para sua ONG ligada ao basquete. Sua identidade a inibe a divulgação de resultados de sua ONG, prejudicando a captação.

Problemas desse tipo quanto ao sub-ótimo podem estar associados à efetuação, segundo Arend, Sarooghi e Burkemper (2015), porque a teoria da efetuação considera implicitamente que os empreendedores fazem uma avaliação precisa dos meios efetuais a sua disposição. Desse modo, a teoria não considera que as pessoas tendem a se auto-iludir e a superavaliar suas habilidades, competências, qualidades, bem como seus outros meios, como informações e redes sociais. Os mesmos autores consideram que a teoria da efetuação contém um otimismo exagerado acerca das habilidades do empreendedor, contradizendo o que se sabe das limitações e vieses cognitivos dos empreendedores, como superconfiança e tendência à teimosia (Busenitz e Barney, 1997).

Dado o importante impacto ilustrado acima da identidade, via efetuação, sobre as atividades empreendedoras, inclusive determinando os tipos de iniciativa e o modo de se empreender particularmente no EEV, esse meio efetual recebe particular atenção neste artigo. Ela pode até mesmo, por vezes, estar associada a um jeito de ser desapegado da cuidadosa e detalhada busca de qualidade por parte do empreendedor, como geralmente se vê nos bricolores. Se isso ocorre, explorála e transferir suas características para o empreendedorismo significa aproximar o perfil do efetuador em questão do jeito de ser do bricolor, que é dado ao emprego de soluções sub-ótimas.

A abordagem da efetuação originalmente "assumes that identity is a given and relative stable precondition of the entrepreneurial process that support the entrepreneur in ordering preferences in the process of effectuating resources, stakeholder commitment, etc.." (Nielsen e Lassen, 2012, p. 373). Mas a literatura em empreendedorismo já assimila uma noção mais flexível e condizente com a realidade dos empreendedores, em especial no EEV: a identidade é um processo dinâmico em contínuo desenvolvimento (Nielsen e Lassen, 2012). O foco aqui é o da "auto-identidade interna - o que o próprio indivíduo assume ser" - mais do que o da "gama de identidades sociais externas - a variedade daquilo que outras pessoas assumem que o indivíduo seja ou, mais formalmente, as noções culturais, discursivas ou institucionais de quem ou o que qualquer indivíduo possa ser" (Watson, 2009 , p. 255). A perspectiva da identidade que adotamos neste trabalho é, portanto, a da psicologia social, tratada por Nielsen e Lassen (2012). Esta é uma das duas perspectivas encontradas no campo do empreendedorismo, sendo a outra advinda da sociologia (Down e Giazitzoglu, 2014). Todavia, a perspectiva sociológica realça algo que é importante para nossa pesquisa: "a identidade está sempre num processo de vir a ser" (Down e Giazitzoglu, 2014) por ser um conjunto de construções temporário, contextual e evolutivo, mais do que fixo e permanente (Alvesson et al., 2008).

\section{Métodos}

Os dados de cinco casos de empreendimentos que se pautavam pela lógica de EEV esportiv

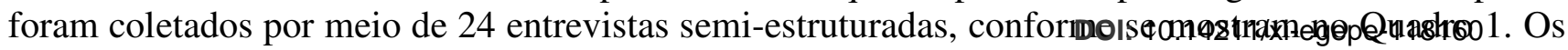


desenvolvimento do EEV, que serão enfocadas na sequência.

Quadro 1: Casos de EEV esportivo

\begin{tabular}{|c|c|c|c|c|}
\hline $\begin{array}{c}\text { Casos } \\
\text { (estado) }\end{array}$ & Atividades & Força de trabalho & $\begin{array}{l}\text { Número de } \\
\text { clientes }\end{array}$ & $\begin{array}{l}\text { Número de } \\
\text { entrevistas } \\
\text { (média de } \\
\text { duração) }\end{array}$ \\
\hline $\begin{array}{l}\text { [C1] } \\
\text { Escola de surfe - } \\
\text { fundada em } 2003 \\
\text { (SC) }\end{array}$ & $\begin{array}{l}\text { Aulas de surfe, treinamento, } \\
\text { preparação física para surfe, } \\
\text { hostel, surf camp, guia de } \\
\text { surfe, competições }\end{array}$ & $\begin{array}{l}2 \text { sócios (ex-casal) para } \\
\text { dar aulas e gerir } \\
2 \text { professores }\end{array}$ & $\begin{array}{l}\text { Verões: } \\
\text { 40/dia }(2003-2012), \\
\text { 15/dia }(2012-2016), \\
\text { 20/dia }(2017-\ldots) \\
\text { Outras estações } \\
\text { 6/dia }(2003-2012), \\
\text { 3/dia }(2012-2016), 5- \\
\text { 10/dia }(2017-\ldots)\end{array}$ & $\begin{array}{c}5 \\
(1 \mathrm{~h} 15 \mathrm{~min})\end{array}$ \\
\hline $\begin{array}{l}\text { [C2] } \\
\text { Viagens para } \\
\text { corredores - } \\
\text { fundada em } 1989 \\
\text { como imobiliária - } \\
\text { convertida para } \\
\text { esportes em } 2006 \\
\text { após aquisição por } \\
\text { esportistas (SP) }\end{array}$ & $\begin{array}{l}\text { Oferta de pacotes de viagem } \\
\text { para corridas no exterior } \\
\text { incluindo reserva de hotel, } \\
\text { inscrição assegurada em } \\
\text { corrida e bilhetes de voo } \\
\text { opcionais para corridas } \\
\text { atrativas (ex.: principais } \\
\text { maratonas internacionais) em } \\
\text { diversos países }\end{array}$ & $\begin{array}{l}2 \text { sócios de } 2006 \text { a } 2018 \text { e } \\
\text { também } 1 \text { empregado de } \\
2018 \text { em diante }\end{array}$ & $\begin{array}{l}15 \text { corredores em } \\
2006 \\
1.500 \text { corredores em } \\
\text { media de } 2015 \mathrm{em} \\
\text { diante }\end{array}$ & $\begin{array}{c}3 \\
(1 \mathrm{~h})\end{array}$ \\
\hline $\begin{array}{l}{[\mathbf{C 3}]} \\
\text { Associação de } \\
\text { corredores e } \\
\text { negócio de esportes } \\
\text { (loja e micro- } \\
\text { indústria) - } \\
\text { fundados } \\
\text { respectivamente em } \\
1987 \text { e } 1990 \\
\text { (RJ) }\end{array}$ & $\begin{array}{l}\text { Associação: training for } \\
\text { running, conviviality, street } \\
\text { and mountain races, travels for } \\
\text { competitions } \\
\text { Negócio: artigos desportivos } \\
\text { em geral, uniformes escolares, } \\
\text { artigos para corridas de rua e } \\
\text { de montanhas }\end{array}$ & $\begin{array}{l}\text { Associação: } 3 \text { diretores } \\
\text { (incluindo um fundador } \\
\text { que é educador físico); } \\
5 \text { voluntários eventuais } \\
\text { Negócio: } 1 \text { proprietário- } \\
\text { gestor, } 2 \text { empregados e } \\
\text { média de } 8 \text { trabalhadores } \\
\text { temporários ao longo do } \\
\text { ano }\end{array}$ & $\begin{array}{l}\text { Associação: } 7 \\
\text { membros na } \\
\text { assembleia de } \\
\text { fundação; } 120 \text { nos } \\
\text { anos } 1990 \text { s, } \\
\text { principalmente } \\
\text { crianças; } 60 \text { em } \\
2019 \text {, crianças não } \\
\text { são mais permitidas. } \\
\text { Negócio: em torno } \\
\text { de } 100 \text { clientes }\end{array}$ & $\begin{array}{c}5 \\
\text { (1h } 10 \mathrm{~min})\end{array}$ \\
\hline $\begin{array}{l}\text { [C4] } \\
\text { Organização social } \\
\text { de bodyboarding - } \\
\text { fundada em } 2009 \text { e } \\
\text { convertida em } 2012 \\
\text { para trabalhar com } \\
\text { crianças e } \\
\text { adolescentes (RN) }\end{array}$ & $\begin{array}{l}\text { Bodyboarding, yoga, aulas de } \\
\text { inglês e de espanhol para } \\
\text { crianças e adolescentes pobres; } \\
\text { eventuais cursos de costura e } \\
\text { de artesanato para suas mães } \\
\text { desde } 2017 \text {; hostel desde } 2018\end{array}$ & $\begin{array}{l}\text { - } 3 \text { fundadores e diretores } \\
\text { - } 2 \text { voluntários }\end{array}$ & $\begin{array}{l}20 \text { crianças e } \\
\text { Eventualmente suas } \\
\text { mães }\end{array}$ & $\begin{array}{c}6 \\
\text { (1h } 30 \mathrm{~min})\end{array}$ \\
\hline $\begin{array}{l}\text { [C5] } \\
\text { ONG de basquete - } \\
\text { fundada em } 2004 \\
\text { (SP) }\end{array}$ & $\begin{array}{l}\text { Atividades lúdicas de basquete } \\
\text { e jogos para crianças e } \\
\text { adolescentes de comunidades } \\
\text { pobres; eventuais serviços de } \\
\text { gestão para outras iniciativas } \\
\text { sociais (tais como patrocínio } \\
\text { da Petrobras para } 100 \text { atletas } \\
\text { olímpicos brasileiros: } 2011 \text { - } \\
\text { 2014) }\end{array}$ & $\begin{array}{l}\text { - } 3 \text { a } 5 \text { diretores desde } \\
2004 \text { (fundadora foi } \\
\text { medalha de prata em } \\
\text { Atlanta em 1996) } \\
\text { - } 5 \text { empregados em } 2004 \\
\text { gradualmente cresceu } \\
\text { para } 25 \text { em } 2018 \\
\text { - } 30 \text { voluntários eventuais } \\
\text { desde } 2015\end{array}$ & $\begin{array}{l}\text { - } 200 \text { em } 2004 \\
\text { - } 1.000 \text { em média } \\
\text { desde } 2015\end{array}$ & $\begin{array}{c}5 \\
(1 \mathrm{~h})\end{array}$ \\
\hline
\end{tabular}

A análise em profundidade das 28 horas de áudio das entrevistas foi realizada por meio do software de análise de dados qualitativos Atlas-ti (Friese, 2014), empregando-se a lógica de alternate template analysis (Langley, 1999) segundo a qual se gera uma lista tentativa de códigos pré-definidos para a análise inicial. Inspirando-nos na técnica utilizada por Fisher (2012) que utilizou os conceitos dos paradigmas de causação, bricolagem e efetuação, sendo que neste trabalho enfocamos sobretudo os dois últimos. Desse modo os dados de campo, bem como os secundários são comparados com os códigos deduzidos da teoria, de tal sorte que verifica-se o grau de aproximação e concordância entre os constructos e os dados.

Ainda que os conceitos de bricolagem, efetuação e causação tenham sido úteis, nenhum deles conseguia explicar, isoladamente, as diferentes fases do processo de EEV esportivo, o que nos levou a trabalhar com os dados com uma codificação aberta complementar, abordando os dados de forma indutiva, segundo Strauss e Corbin (2014).

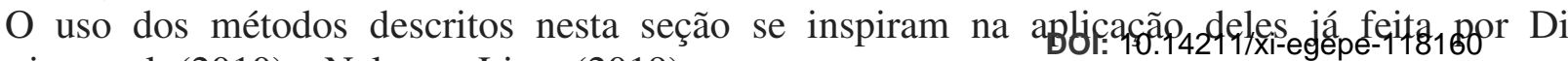


A análise dos dados revelou uma contribuição adicional de nossa pesquisa a partir do emprego de uma abordagem processual do empreendedorismo. Os estudos do EEV podem então contar agora com um novo modelo de compreensão, estruturado em quatro fases de desenvolvimento do EEV: Fase A- emergência do EV e de meios para se empreender; Fase B- desenvolvimento do EEV; Fase C- renovação; e Fase D- preparação do futuro. Elas são detalhadas nas subseções a seguir como pano de fundo para os demais resultados.

\subsection{Fase A- Emergência do EV e de Meios para se Empreender}

Essa primeira fase se caracteriza pelo surgimento do vínculo do empreendedor com seu estilo de vida ( $\mathrm{C} 1 \mathrm{com}$ o surfe, $\mathrm{C} 2 \mathrm{com}$ a corrida de rua, $\mathrm{C} 3 \mathrm{com}$ a corrida e treinamento para corrida, $\mathrm{C} 4$ com o body boarding e C5 com o basquetebol), bem como o desenvolvimento de meios úteis para se empreender com bricolagem e efetuação. Com uma exceção (C2), o vínculo com o EV iniciou-se quando os empreendedores eram crianças ou adolescentes e experimentaram os esportes por influência de familiares ou amigos, continuando sua prática até esta se firmar como EV esportivo.

$\mathrm{Na}$ prática do esporte, os ainda pré-empreendedores desenvolveram meios para realizar bricolagem e efetuação: a rede de relação com outros praticantes, treinadores, desportistas, apoiadores, patrocinadores etc.; conhecimentos diversos sobre a organização da prática esportiva e da própria prática (casos $\mathrm{C} 1$ a C5); experiência com a gestão do esporte (C1, C3, C4 e C5). Em vários casos (C1, C3 e C4), houve alguma experiência empreendedora até mesmo com gestão de esportes. Em outros ( $\mathrm{C} 1$ e $\mathrm{C} 2)$, as experiências e contatos transcenderam o círculo esportivo. Quanto aos materiais (pranchas de surfe, bolas de basquete etc.) e outros recursos necessários ao início do EEV, foram em boa parte acumulados na fase A para uso na fase B, inclusive por bricolagem e efetuação.

$\mathrm{O}$ caso C2 ilustra essas ideias. Nele, os sócios aproveitaram suas competências de comunicação em Inglês, suas experiências com viagem e residência no exterior e boas relações com a dona de uma agência de aluguel de imóveis estrangeiros. Passaram da fase A para a B. Acreditando poder aproveitar bem esses meios, conseguiram negociar condições facilitadas para adquirir a empresa e aplicaram considerável dose de efetuação no negócio. Todavia, a empresa sofreu forte declínio devido à competição da ascendente Airbnb e a uma desaceleração econômica. A saída encontrada articulou sua rede de contatos na Disney de Orlando e suas experiências como corredores de rua amadores. Usaram bricolagem recombinando recursos, também convertendo a empresa em uma agência de viagens ao exterior para corredores de rua. Usaram efetuação explorando seus meios (identidade de corredores de rua, conhecimentos e relações) minimizando riscos.

A fase A para os cinco casos estudados já denota elementos de bem-estar e prazer associados ao trabalho e ao esporte de predileção a serem respeitados e cultivados por cada empreendedor no empreendedorismo, como ilustra a citação:

Eu era diretor e treinador voluntário numa associação, pelo prazer que a corrida [inclusive corrida feita por outros] me dava - e me dá até hoje. Mas é errado dizer que eu não ganhava algo com isso. Eu não ganhava financeiramente. Mas eu ganhava uma projeção na cidade [prestígio] que me ajudava em outros setores profissionais... (Alexandre - C3.)

Alexandre desenvolveu meios que foram aproveitados depois para empreender na fase B. Por exemplo, fez evoluir sua identidade (passando a se ver como organizador de eventos, algo explorado ao empreender), obteve conhecimentos (quanto a oferecer treinos e competições, explorados no empreendedorismo) e cresceu em prestígio.

Houve também mudança de identidade para os vários pré-empreendedores ao longo de suas práticas esportivas até que chegasse um momento relevante de manifestação do que podemos chamar de hipertrofia da identidade de estilo de vida (HIEV). Em C1, por exemplo, os dois surfistas e educadores físicos casados se viam inicialmente como professores de educação física que surfavam esporadicamente. Porém, começaram a dar aulas de surfe poucos anos antes de abrir sua própria escola dedicada ao esporte, o que os levou a mudar sua identidade. Passaram a se ver mais como

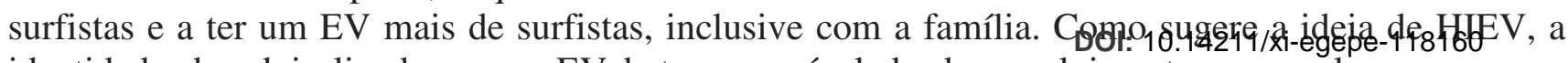


impulsionado também pelos lucros da empresa.

\subsection{Fase B- Desenvolvimento do EEV}

A fase $\mathrm{B}$ se inicia com o começo do EEV. Está normalmente associada à criação de uma organização. Mas é possível outra situação, como a transição para o EEV em uma organização já existente. Esse foi o caso de C2, no qual o empreendedorismo começou com uma empresa comprada e, pouco depois, foi convertido por bricolagem ao EEV baseado na venda de pacotes de viagem esportiva. Para todos os casos, houve alguma bricolagem e alguma causação, com previsões e elementos de planejamento, no período de fundação. Não obstante, a efetuação esteve amplamente presente porque os empreendedores exploraram identidade, relações e conhecimentos que emergiram em seu EV. Estabeleceram objetivos que esses meios permitiam buscar e procuraram empreender sem ultrapassar um limite de perdas aceitáveis. O processo gradual de criação de $\mathrm{C} 1$ exemplifica isso. A progressão de baixo risco com a saída gradativa do casal Vitória e João de seus empregos e de um negócio prévio ocorreu à medida que se sentiam confiantes e sua condição financeira melhorou.

Todas as empresas (visando lucro) da amostra $(\mathrm{C} 1, \mathrm{C} 2$ e parte das atividades em $\mathrm{C} 3)$ têm a atividade empreendedora como fonte principal de remuneração e de financiamento do EV dos empreendedores. Nesse sentido, as práticas hedonistas ligadas ao esporte puderam se expandir, aperfeiçoar e/ou sofisticar à medida que se aperfeiçoaram as atividades empreendedoras, permitindo mais remuneração e reserva financeira. A situação é outra nas organizações sociais. Em C4, vê-se um ator principal, Alice, com uma identidade associada a uma postura anti-consumista e a uma opção de vida com recursos módicos. Assim, este é um caso de baixa pulsão por geração de renda, consonante com a condição de C4 ser o caso de maior restrição financeira da amostra. Em C5, a fundadora principal é uma medalhista olímpica de prata que se aposentou relativamente jovem, aos 38 anos. Sua reserva financeira da aposentadoria lhe deu certa tranquilidade para se concentrar no empreendedorismo social sem grande preocupação com remuneração.

Muitas ocorrências de efetuação e bricolagem, entremeadas por alguma causação, se deram desde o início do EEV nos cinco casos. Como mostrou a descrição da fase A, o EV em cada caso foi uma relevante base para que os empreendedores efetuassem e usassem bricolagem, principalmente frente a dificuldades de recursos e outras limitações, situação em que virar-se com o que se tem (making do) e rejeitar limitações (refuse to enact limitations) são processos decisivos. O caso C2 é emblemático nesse aspecto. Nele, os dois sócios exploraram a efetuação na compra da imobiliária, com início promissor. Mas enfrentaram uma baixa abrupta de demanda devido ao crescimento do concorrente Airbnb. Tiveram que recriar a empresa, convertendo-a em agência de viagem para corredores de rua. A conversão ocorreu sob influência de uma HIEV emergente e foi, mais exatamente, uma bricolagem-efetuação (bricofetuação?). O processo combinou "virar-se com o que se tem", "rejeitar limitações" e a exploração de meios efetuais ancorados no EV dos dois sócios. A HIEV emergente (que surge durante a transição para o EEV) ou pré-existente (surgida antes da transição para o EEV) marcou em todos os casos um ápice da identidade como determinante do EEV.

A identidade dos empreendedores é central para todos os casos e fases. Desde o início do EEV, o conceito de si mesmo (auto-identidade) quanto ao que e quem se é, e a quem se quer ser, é definidor da intenção e das iniciativas empreendedoras. Assim, a identidade é um importante determinante da iniciativa de se tornar empreendedor de estilo de vida, das características do EEV e dos esforços para desenvolvê-lo ao longo do tempo. Foi nesse sentido que emergiu indutivamente dos dados o conceito de HIEV.

A mudança gradativa de identidade dos empreendedores na escola de surfe $(\mathrm{C} 1)$ descrita na seção precedente nos levou a investigar melhor o tema. Observamos outras condições e consequências da identidade dos empreendedores ao longo do processo de EEV. Uma das consequências é que, na situação que estudamos de estilo de vida precedente ao EEV, o início do processo de EEV se dá em parte pelo transbordamento de aspectos de identidade, que conduzem o ator a empregar certos comportamentos e artefatos, como o modo escoblido. 
particularmente importante do processo do EEV devido à HIEV .

O conceito emergente de HIEV é descrito no Quadro 2.

\section{Quadro 2- Definição de conceitos emergentes}

Hipertrofia da identidade de estilo de vida (HIEV): adicionalmente à identidade empreendedora, os empreendedores normalmente possuem outras identidades (Shepherd \& Haynie, 2009); assim, a HIEV é relativa à identidade que se destaca por efeito de um EV específico (ex.: ser surfista, ser jogadora de basquete...) e direciona o comportamento do empreendedor especialmente para atividades alinhadas com o EV.

Momento da HIEV (pré-existente e emergente): é o momento no qual a HIEV existe e pode conduzir o empreender a atividades alinhadas ao EV priorizado; de acordo com nossos dados, a HIEV pode ser pré-existente em relação ao início do EEV ou emergente, quando ela emerge durante o começo desse processo.

Efeitos da HIEV (moderação e intensificação): são resultados da característica direcionadora da HIEV; a moderação é um efeito de mitigação do HIEV sobre as atividades, com o intuito de prevenir ou eliminar perturbações no EV (ex.: diminuir o trabalho para ter tempo de surfar com amigos); e a intensificação é um efeito reforçador da HIEV sobre as atividades de tal modo que estas contribuam mais para o desenvolvimento do EV (ex.: trabalhar mais para pagar uma viagem de surfe a ocorrer em alguns meses).

Destacam-se nos dados, assim como na literatura, os efeitos positivos da identidade e de outros meios efetuais para o empreendedorismo. Uma ilustração adicional dos efeitos positivos da efetuação é que, a partir da experiência dos empreendedores, a efetuação deles pode até mesmo promover a causação, transferindo elementos dela para novas iniciativas empreendedoras. Essa é uma ideia nova e contraintuitiva frente à literatura. Em $\mathrm{C} 1$, os dois empreendedores formados em educação física relataram que transferiram proveitosamente para seu EEV esportivo conhecimentos e hábitos quanto à fixação de metas e objetivos, comuns para guiar treinos e se obter resultados pretendidos em competições esportivas. Essa sobreposição da efetuação com a causação repetiu-se em outros casos de nosso estudo com o uso de controles, fichas, registros, planilhas e fixação de metas como fruto de experiências precedentes. O uso da causação, contudo, manteve-se modesto e não expurgou a efetuação e a bricolagem. A variedade de lógicas empreendedoras permitiu aproveitar cada uma delas e suas combinações quando os desafios vividos pareciam demandar isso.

Os efeitos da identidade e de outros meios efetuais também podem ser negativos para o empreendedorismo, como mostram os dados. $\mathrm{O}$ fato é relevante e pouco compreendido nas pesquisas. $\mathrm{O}$ jeito de ser e de fazer, uma componente central da identidade, pode ser fonte de impactos negativos. Por exemplo, Patrícia (ex-profissional de basquete em C5) transferiu para seu jeito de empreender e para sua ONG o aprendizado do esporte de que o apoio de terceiros ocorre como consequência de resultados auto-evidentes mostrados em competições, sem necessidade de o atleta fazer divulgação. Ela não conseguiu se ajustar ao fato de que no empreendedorismo os resultados não são auto-evidentes como no esporte. Ela usa uma metáfora simples para explicar a introversão e a dificuldade de sua ONG quanto a divulgar resultados e assim obter patrocínios e financiamentos: "não sabemos cacarejar quando pomos ovos e isso vem de minha aprendizagem no esporte". Uma dimensão não percebida (ponto cego - Arend, Sarooghi e Burkemper, 2015) na ONG desde o início do EEV é a necessidade de se ajustar ao novo contexto, no qual a competição por fontes de recurso e engajamento de stakeholders deve ser enfrentada com ampla divulgação de resultados.

Sinergias podem ocorrer não só entre aspectos da efetuação e da bricolagem que favorecem o empreendedorismo, mas também entre aspectos que o dificultam. Uma possibilidade é que, ao efetuar na realização de uma nova iniciativa empreendedora, uma pessoa que teve experiências satisfatórias com a bricolagem tenderia a ter aspectos da bricolagem em seu repertório de meios efeituais (identidade, conhecimentos/experiências e relações) e a explorá-los. Trata-se de um processo semelhante ao descrito acima, de promoção da causação feita pela efetuação. Um exemplo de nossos dados vem novamente de $\mathrm{C} 1$ e refere-se a donos de uma escola de natação começando uma escola de surfe. Após terem empregado (satisfatoriamente, segundo a avaliação deles) diferentes aspectos da bricolagem na primeira empresa (incluindo soluções sub-ótimas, como o uso de equipamentos reparados e em sobrevida ou de materiais em aplicações alternativas) apbos podem transpor esse 
ótimo feito por eles mesmos (ex.: remendadas e com estética questionável), podem não atentar para eventuais efeitos nocivos. A prática pode ferir a imagem de seu trabalho e de seu negócio - e consequentemente a obtenção e a fidelização de clientes.

Nos diferentes casos estudados, uma variedade de traços de identidade mostra-se associada a efeitos indesejados da efetuação e da bricolagem sobre as atividades empreendedoras, como a introversão sendo contraprodutiva nas relações com clientes $(\mathrm{C} 2)$ e um estilo rústico que incomoda ou afugenta clientes e associados, redundando em soluções sub-ótimas eventualmente percebidas como falta de profissionalismo (C1, C3 e C4). Por exemplo, o jeito despojado de Alexandre em C3 relaciona-se aos aspectos de sua identidade. Trata-se de um bricoleur clássico (Baker e Nelson, 2015), que é multi-habilidoso, autodidata para tarefas manuais e não credenciado nisso, mas que tem experiência útil em muitas atividades. Fora sua formação e seu trabalho em educação física, ele tem experiência e autodidatismo em atividades de instalação elétrica, obras, pintura e soluções materiais sub-ótimas para atividades esportivas, entre outras. Todavia, o hábito do empreendedor quanto à alta frequência de uso e ao tipo de coisa em que aplica as soluções sub-ótimas faz com que muitos vejam sinais demasiados de precariedade em suas realizações.

Em C1, traços hedonistas de identidade em João frequentemente se chocam com a ideia de dar aulas continuamente e com atenção intensa dedicada aos alunos, como sua clientela tenderia a preferir. Por exemplo, a participação dele em competições máster (para "veteranos") no surfe o leva às vezes a deixar de atender alunos desejosos por aulas em um dado fim de semana. Por outro lado, seu prazer em surfar mais e mais o leva a dar frequentemente aulas mais longas do que o combinado com seus alunos, o que agrada a estes. Mostrando vantagem sobre vários outros professores de surfe, ele se desenrola com certo sucesso (e rejeita limitações) para falar línguas estrangeiras e atende alunos de outros países. Entretanto, essa solução sub-ótima pode não agradar a uma parcela dos clientes, dispostos a pagar melhor pelos serviços. O mesmo pode ocorrer com clientes de qualquer nacionalidade que usam as muitas pranchas de surfe de sua escola que tiveram reparo sub-ótimo e ficam esteticamente pouco atrativas (ex.: reparos com fita adesiva). Como destacaram Senyard et al. (2014), a insistência neste tipo de solução dificulta a atração de clientes exigentes. Outro exemplo é o de $\mathrm{C} 4$ que, inicialmente, criou pranchas de bodyboarding com garrafas pet amarradas, algo que se mostrou inadequado para o esporte. O processo de ensaio e erro, muitas vezes utilizado na bricolagem, pode levar a soluções muito precárias (Lanzara,1999).

\subsection{Fase C- Renovação}

A fase $\mathrm{C}$ concentra esforços de recuperação frente a graves dificuldades para o desenvolvimento do EEV e do próprio EV dos empreendedores. As dificuldades são principalmente aquelas percebidas como inibidoras da disponibilidade de recursos e das chances de desenvolvimento, em especial quando ameaçam a manutenção do EV. A superação feita pelos empreendedores pode contar com a efetuação e a bricolagem. Esses dois comportamentos podem se mesclar com ou ser entrecortados pela causação, em especial quando há decisões com análises e previsões, assim como planos para recuperação.

Exemplos das dificuldades que demandam renovação são: aumento de custos dos negócios e com gastos pessoais de sócios que eram um casal e passaram a morar em casas separadas (C1); maior desafio para captar clientes e receitas vindas deles $(\mathrm{C} 1$ e $\mathrm{C} 3)$ ou de financiadores/doadores $(\mathrm{C} 3, \mathrm{C} 4$ e C5); inadimplência de um grande cliente, como na perda de R\$ 60 mil pela empresa (C3); cortes de pessoal e outros recursos em projetos de financiamento governamental (C5); falta de fluxo estável e sustentável de doações privadas e de auxílio de voluntários (C3, C4 e C5). Esse último problema levou ao fechamento, em 2013, de uma das unidades de C5 que atendia 200 crianças. Nesse sentido, a fase $\mathrm{C}$ tende a ser um período de frequente uso da bricolagem e da efetuação. Pode também haver nela um trabalho esporádico de causação, como na reformulação estatutária de C5 em 2013 para ampliar a captação de doações de pessoas físicas.

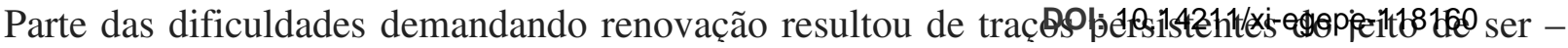


características reveladas pelos dados: perfil que denota baixo nível de exigência com qualidade e profissionalismo nas atividades, levando à geração e oferta de soluções sub-ótimas (C1, C3 e C4); tolerância a condições de trabalho vistas como caóticas por aqueles mais exigentes quanto ao profissionalismo (C1, C3 e C4); jeito reservado ou introspectivo inibindo a manifestação de carisma junto à clientela e consequente ampliação da rede de relação (C2); jeito relativamente descompromissado e caótico de um bricolor (C3); modesto domínio de técnicas de gestão e da sensibilidade mercadológica facilitando o engano quanto à atratividade de nomes, ideias e formas de divulgação $(\mathrm{C} 1, \mathrm{C} 3$ e $\mathrm{C} 4)$; dificuldades quanto ao reconhecimento do potencial do prestígio e à habilidade para buscá-lo e empregá-lo na rede de relação para se obter e fidelizar financiadores, voluntários, clientes e facilitadores $(\mathrm{C} 1, \mathrm{C} 2, \mathrm{C} 3$ e $\mathrm{C} 4)$. Na origem dessas dificuldades, parece residir uma avaliação imprecisa dos (usos possíveis de) meios a disposição, sejam relativos a identidade, experiência e conhecimento ou a recursos e informações disponíveis até mesmo a partir da rede de relação. Tal debilidade provoca erros de decisão e ação associados a atividades e escolhas contraprodutivas, além de poder manter a insistência no uso de soluções sub-ótimas com efeitos indesejáveis (Arend, Sarooghi e Burkemper, 2015).

A escola de surfe (C1) e uma organização social (C4) responderam a suas dificuldades buscando se renovar com diminuição de custo e aumento de receita, usando iniciativas que incluíram a bricolagem quanto à recombinação de recursos escassos. As duas converteram o espaço da sede que já acomodava a moradia de um dos diretores (ambos os casos) - para novas finalidades, abrigando um hostel, cada uma. $\mathrm{O}$ objetivo da diversificação com bricolagem objetivou obter mais clientes, colaboradores, divulgadores de suas atividades e receita.

No caso de $\mathrm{C} 4$, a organização de maior restrição financeira da amostra, a rede de relação já lhe oferecia parceiros e doadores que pagavam o aluguel da sede. Ademais, a partir de 2018, o hostel de $\mathrm{C} 4$ passou a cobrir metade de seus custos restantes anuais. E, nesse mesmo ano, os diretores aboliram o lanche oferecido às crianças do projeto de bodyboarding para comunidades carentes e passaram a pagar, do próprio bolso, metade do valor do material de limpeza. C1 também obteve mais clientes e receita com seu hostel e com outras diversificações: 1) com efetuação - preparação física extra-mar para alunos de surfe, venda de material instrutivo online sobre surfe; 2) com um misto de bricolagem e efetuação - surf trips com deslocamento na região e surf camps no hostel.

Obter mais recursos e ser mais eficiente no uso daqueles disponíveis tornou-se, portanto, mais importante na fase $\mathrm{C}$ para os cinco casos dado que todos eles viveram essa realidade: "estamos tentando sobreviver com a estrutura que temos, que já é super enxuta" (Igor - C5).

\subsection{Fase D- Preparação do Futuro}

A fase D marca um afastamento significativo da bricolagem, dado que é uma fase de preparação para o porvir, e não de efetiva resposta imediata a novos problemas ou oportunidades correntes. Nesse sentido, a fase se caracteriza por uma mescla de efetuação e causação. Nessa fase, ganha relevância novamente a diversificação, além da captação e da fidelização de clientes, parceiros e outros colaboradores, somadas a eventuais outras iniciativas para desenvolvimento futuro.

$\mathrm{O}$ uso das parcerias pode ser exemplificado por C2. Desde o início da agência de viagem para corredores, mesmo experimentando crescimento constante do faturamento, C2 enfrenta uma concorrência mais agressiva e os desafios de alta do dólar combinada à instabilidade econômica brasileira. Assim, tem apostado numa solução tipicamente efetual, as parcerias, buscando tirar o melhor de sua rede de relação com benefícios mútuos e baixo risco. A partir de 2017, desenvolveu parcerias com lojas de material esportivo oferecendo descontos aos clientes de C2, com profissionais para aconselhamento aos clientes e com uma agência de modelos, a viajarem para correr.

Rejeitando limitações e dando seu jeito com o que têm para resolver problemas, além de empregar a efetuação, os diretores das cinco organizações enfrentaram desafios variados para garantir o futuro destas com a busca e gradual exploração de novos jeitos e soluções. No entanto, alguns deles

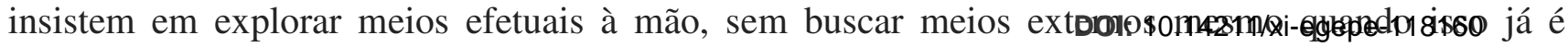


Contudo, ela não tem se mostrado comprometida e faz pouco do trabalho. Isso restringe a atividade de divulgação para obtenção e fidelização de clientes. A insistência do pai com essa solução efetual sub-ótima não o deixa progredir para uma solução efetiva. Esse é um risco para do empreendedorismo em geral, como alertaram Arend, Sarooghi e Burkemper (2015).

As duas últimas fases do processo de EEV continuam a ter a identidade (assim como a afirmação e a evolução desta) como base de diferentes resultados, inclusive em diversificação. Por exemplo, em $\mathrm{C} 1$, a identidade individual dos dois sócios, que eram um casal, influenciou para a separação matrimonial dos dois em 2014, ainda que tenham se mantido como sócios. Influenciou novamente em 2016 para que buscassem suas respectivas marcas de serviço na mesma empresa, para melhor expressarem sua individualidade e as diferenças de seus serviços. Ele focou novas atividades de condicionamento físico e aulas para alunos de nível intermediário e ela, aulas para alunos em geral e a inovação com venda de material instrutivo na internet.

\section{Discussão e Conclusões}

Este trabalho mostrou como as abordagens teóricas da efetuação (Sarasvahty, 2001, 2008) e da bricolagem (Baker e Nelson, 2005), em suas complementaridades, diferenças e sinergias, ajudam a explicar o socioeconomicamente importante EEV em seu processo ao longo do tempo. Assim, o trabalho gera avanço com o inabitual, mas necessário, acolhimento do tema do EEV na comunidade acadêmica de pesquisa do empreendedorismo. Faz também a contribuição de auxiliar nos passos iniciais de se aplicar teorias especificamente do empreendedorismo a esse tema que, claramente, está intimamente ligado a esse campo de estudo. O estudo, trazendo o diferencial de estudar casos de empreendedorismo empresarial, social e misto, ainda complementa as poucas pesquisas existentes (ex.: Nelson e Lima, 2019; Scazziota, 2019; Servantie e Rispal, 2018) a explorarem empiricamente as sinergias e interseções da bricolagem com a efetuação.

Um diferencial central de nosso estudo é a atenção detalhada dada à identidade do empreendedor segundo seu desenvolvimento processual ligado ao EEV, sendo a identidade um determinante importante de intenções, escolhas e práticas do EEV. O EEV mostrou-se em grande parte como um esforço de expressão, e por vezes de desenvolvimento, da identidade do empreendedor. Considerada habitualmente como um meio efetual (Sarasvathy, 2001), a identidade mostrou-se também como um definidor relevante da bricolagem - inclusive embasando suas características de desapego ao profissionalismo e de uso de soluções sub-ótimas - a contribuir para a geração de soluções em condições de grande restrição de recursos.

Para além do exame dos elementos de efetuação, bricolagem e até de causação encontrados nas atividades empreendedoras estudadas, este trabalho contribui com novos conceitos ligados à identidade, como é o caso da HIEV. O conceito indica que, a depender da intensidade de uma identidade do empreendedor ligada a um estilo de vida priorizado, ela pode se mostrar hipertrofiada, se destacando em relação às demais possíveis identidades que ele tem, e, como forma de expressar-se, motiva o empreendedor de estilo de vida a buscar no EEV atividades alinhadas a seu EV. Também caracterizou-se que o HIEV tem efeitos de moderação e de intensificação respectivamente em situações que podem atrapalhar ou ajudar no EV que se quer viver e desenvolver. Outra contribuição foi a análise e a demonstração das fases que os empreendedores percorrem, desde o desenvolvimento da uma identidade ligada a um EV que impulsiona o indivíduo ao EEV.

Os resultados mostraram também que nem todos os efeitos da efetuação e da bricolagem são benéficos às atividades empreendedoras, visto que podem também ocasionar, em alguns casos, estilos despojados, rústicos ou introvertidos de tratamento de clientes, bem como a criação e oferecimento de soluções sub-ótimas, que podem gerar problemas de qualidade ou soar como falta de profissionalismo.

A ideia de geração de efeitos indesejáveis soa estranha ao se tratar da efetuação, já que é quase unânime a perspectiva que põe a efetuação do lado oposto a essa possibilidade. $\mathrm{O}$ mesmo não ocorre

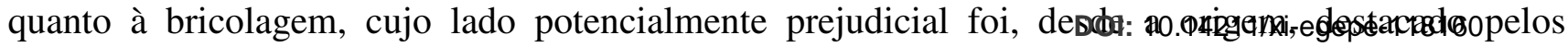


normalmente considerados não tão bons quanto o recomendável devido à própria escassez de recursos, mas também pelo jeito de ser do bricolor, normalmente afeito ao "dar um jeitinho" ou a usar soluções de qualidade questionável. Os autores também explicam que o uso da bricolagem paralela (em diferentes frentes ao mesmo tempo) por um longo período, sem transição para soluções aperfeiçoadas, fará com que novas ações sejam forçadas a ocorrer em um campo social e econômico limitado usando-se métodos e recursos fora de padrão. "Em outras palavras, a bricolagem paralela ocorrerá restringindo as ações futuras a ciclos contínuos de virar-se com o que está à mão, o que, por sua vez, limita a escala e o escopo da empresa" (Nelson e Lima, 2019, tradução nossa).

Curiosamente, algo semelhante pode ocorrer também com a efetuação, ainda que a literatura não tenha estudado a questão em detalhe. A efetuação pode receber a infusão de soluções sub-ótimas e uma dose da rejeição de limitações, comum à bricolagem, quando o repertório de meios de um efetuador não é bem adequado ao enfrentamento de certos desafios, mas ainda tem alguma utilidade para tanto. O desenvolvimento do conceito de efetuação estendida (Nelson e Lima, 2019) ajuda a ilustrar situações desse tipo. O conceito emergiu do estudo do empreendedorismo social respondendo às consequências do grande desastre natural ocorrido na região serrana fluminense em janeiro de 2011. O conceito é definido como um processo pelo qual atores (que poderiam ser chamados de efetuadores em situações de completa efetuação) ajudam a realizar fins para os quais acreditam ter meios úteis, ainda que esses meios não sejam os mais adequados para tanto.

\section{Referências}

Alvesson, M., Ashcraft, K. L. \& Thomas, R. (2008). Identity Matters: Reflections on the Construction of Identity Scholarship in Organization Studies. Organization, 15(1), 5-28.

Arend, R. J.; Sarooghi, H.; \& Burkemper, A. C. (2015). Effectuation As Ineffectual? Applying the 3E Theory-Assessment Framework to a Proposed New Theory of Entrepreneurship. AMR, 40, 630 651. DOI: $10.5465 / \mathrm{amr} .2014 .0455$

Ateljevic I. \& Doorne S., (2000). Staying within the Fence: Lifestyle Entrepreneurship in Tourism. Journal of Sustainable Tourism, 8(5), 378- 392.

Bacq, S., L. F. Ofstein, J. R. Kickul, and L. K. Gundry. 2015. Bricolage in Social Entrepreneurship: How Creative Resource Mobilization Fosters Greater Social Impact. The International Journal ofEntrepreneurship and Innovation, 16 (4), 283-289.

Baker, T., Miner, A., \& Eesley, D. (2003). Improvising firms: bricolage, account giving and improvisational competencies in the founding process. Research policy, 32(2), 255-276

Baker, T., \& Nelson, R. E. (2005). Creating something from nothing: resource construction through entrepreneurial bricolage. Administrative Science Quarterly, 50(3), 329-366.

Bourdieu, P. (1984). Distinction: A Social Critique of the Judgement of Taste. Cambridge, MA: Harvard University Press.

Busenitz, L. W. \& Barney, J. B. (1997). Differences between entrepreneurs and managers in large organizations: Biases and heuristics in strategic decision-making. Journal of Business Venturing, 12(1), 9-30.

Breysse, M. G. (2016). L'entrepreneur "lifestyle". Revue de l'Entrepreneuriat, 15(3), 231-256.

Carter, N. M., Gartner, W. B., \& Reynolds, P. D. (1996). Exploring start-up event sequences. Journal of Business Venturing, 11, 151-166.

Ciborra, C. U. (1996). The platform organization: Recombining strategies, structures and surprises. Organization Science, 7(2), 103-118.

Daskalopoulou, A., \& Skandalis, A. (2018). Consumption field driven entrepreneurship (CFDE) How does membership in the indie music field shape individuals' entrepreneurial journey. European Journal of Marketing, 53(1), 63-82. DOI:10.1108/EJM-06-2017-0424DOI: 10.14211/xi-egepe-118160 
6520.2010.00370.x

Down, S., \& Giazitzoglu, A. (2014). Identity and entrepreneurship. Routledge Companion to Entrepreneurship. London: Routledge, 102-115.

Fisher, G. (2012). Effectuation, causation, and bricolage: A behavioral comparison of emerging theories in entrepreneurship research. Entrepreneurship Theory and Practice, 36(5), 1019-1051.

Friese, S. (2012). Qualitative Data Analysis with ATLAS.ti. London: SAGE Publications Limited.

Grégoire, D.A., \& Cherchem, N. (2019). A structured literature review and suggestions for future effectuation research. Small Business Economics. DOI: 10.1007/s11187-019-00158-5.

Grivins, M., Keech, D., Kunda, I., \& Tisenkopfs, T. (2017). Bricolage for Self-Sufficiency: An Analysis of Alternative Food Networks. Sociologia Ruralis, 57(3), 340-356.

Guercini, S., \& Cova, B. (2018). Unconventional entrepreneurship. Journal of Business Research, 92, 385-391.

Heilbrunn, S. (2019). Against all odds: refugees bricoleuring in the void. International Journal of Entrepreneurial Behavior \& Research. DOI: 10.1108/IJEBR-10-2017-0393

Hindle, K., \& Senderovitz, M. (2010). Unifying three contending approaches to explaining early stage entrepreneurial decision-making and behaviour. In The Babson College Entrepreneurship Research Conference (BCERC), Lausanne, Switzerland: Babson College.

Johannisson, B. (2004). Entrepreneurship in Scandinavia: bridging individualism and collectivism. In: Guido Corbetta, Morton Huse, Davide Ravasi. Crossroads of Entrepreneurship, pp. 225-241.

Kickul, J, Griffiths, M., Bacq, S. \& Garud, N. (2018) Catalyzing social innovation: is entrepreneurial bricolage always good? Entrepreneurship \& Regional Development, 30(3-4), 407-420. DOI: 10.1080/08985626.2017.1413771

Langley, A. (1999). Strategies for theorizing from process data. Academy of Management Review, 24, 691-710.

Lanzara, G. F. 1998. Self-destructive processes in institution building and some modest countervailing mechanisms. European Journal of Political Research, 33, 1-39.

Lévi-Strauss, C. (1962). The savage mind. Chicago: The University of Chicago Press.

Lima, E. O \& Lopes, R. M. A. (2019). Efetuação, Bricolagem e Empreendedorismo de Estilo de Vida Esportivo. Anais do XLIII Encontro Nacional da Associação Nacional de Pós-Graduação e Pesquisa em Administração, São Paulo, SP.

Maritz A., Beaver B., (2006). The new Zealand "lifestyle" entrepreneur, Human capital. Regional Frontiers of Entrepreneurship Research, 741-754.

Moorman, C., \& Miner, A. S. (1998). The convergence of planning and execution: improvisation in new product development. Journal of Marketing, 62, 1-20.

Nash L., Stevenson H. (2004). Just enough: Tools for creating success in your work and life. New Jersey: John Wiley \& Sons.

Nelson, R., \& Lima, E. (2019). Effectuations, social bricolage and causation in the response to a natural disaster. Small Business Economics. DOI: 10.1007/s11187-019-00150-z

Nielsen, S. L., \& Lassen, A. H. (2012). Identity in entrepreneurship effectuation theory: a supplementary framework. International Entrepreneurship and Management Journal, 8(3), 373-389.

Read, S., Song, M., \& Smit, W. (2009). A meta-analytic review of effectuation and venture performance. Journal of Business Venturing, 24(6), 573-587.

Sarasvathy, S. (2001). Causation and effectuation: toward a theoretical shift from economic inevitability to entrepreneurial contingency. Academy of Management Review, 26, 243-263.

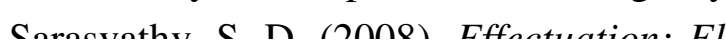
DOl: 10.14211/xi-egepe-118160 
Sarasvathy, S. D \& Dew, N. (2005). New Market Creation Through Transformation. Journal of Evolutionary Economics, 15, 533-565. DOI: 10.1007/s00191-005-0264-X

Sarasvathy, S., Foster, W., \& Ramesh, A. (no prelo). De Cachos Dourados a Gump: Mecanismos Empreendedores para Empreendedores do Dia a Dia. REGEPE - Revista de Empreendedorismo e Gestão de Pequenas Empresas.

Sarasvathy, S., Kumar, K., York, J. G., \& Bhagavatula, S. (2014). An effectual approach to international entrepreneurship: Overlaps, challenges, and provocative possibilities. Entrepreneurship: Theory and Practice, 38(1), 71-93.

Scazziota, V. V. (2019). Knowledge frontiers in entrepreneurship: effectuation and bricolage. (Tese de Doutorado, - Fundação Getulio Vargas, Escola de Administração de Empresas de São Paulo). Recuperado de: https://bibliotecadigital.fgv.br/dspace/handle/10438/27893

Senyard,J., Baker, T. \& Davidsson, P. (2009). Entrepreneurial bricolage: towards systematic empirical testing. Frontiers of Entrepreneurship Research, 29(5), Article 5. Recuperado de: http://digitalknowledge.babson.edu/fer/vol29/iss5/5

Senyard, J., Baker, T., Steffens, P., \& Davidsson, P. (2014). Bricolage as a path to innovativeness for resource constrained new firms. Journal of Product Innovation Management, 31(2), 211-230.

Servantie, V. \& Rispal, M. H. (2018). Bricolage, effectuation, and causation shifts over time in the context of social entrepreneurship. Entrepreneurship \& Regional Development, 30(3-4), 310-335. DOI: $10.1080 / 08985626.2017 .1413774$

Shepherd, D. A., \& Haynie, J. M. 2009. Family business, identity conflict, and an expedited entrepreneurial process: A process of resolving identity conflict. Entrepreneurship Theory and Practice, 33, 1245-1264.

Strauss, A., \& Corbin, J. (2014). Basics of qualitative research: Techniques and procedures for developing grounded theory. Thousand Oaks: Sage.

Stinchfield, B. T., Nelson, R. E., \& Wood, M. S. (2013). Learning From Lévi-Strauss' Legacy: Art, Craft, Engineering, Bricolage, and Brokerage in Entrepreneurship. Entrepreneurship Theory and Practice, 37(4), 889-921.

Watson, T. J. (2009). Entrepreneurial Action Identity Work and the Use of Multiple Discursive Resources: The Case of a Rapidly Changing Family Business. International Small Business Journal, 27(3), 251-274.

Welter, C., Mauer, R., \& Wuebker, R. (2016). Bridging Behavioral Models and Theoretical Concepts: Effectuation and Bricolage in the Opportunity Creation Framework. Strategic Entrepreneurship, 10(1), 5-20. 